Georgia State University

ScholarWorks @ Georgia State University

\title{
Drug Sellers' Neutralizations of Guiltless Drug Sales and Avoidance of “Drug Dealer” Identities
}

Timothy Dickinson

University of Texas at El Paso, tedickinson@utep.edu

Scott Jacques

Georgia State University, sjacques1@gsu.edu

Follow this and additional works at: https://scholarworks.gsu.edu/cj_facpub

Part of the Criminology and Criminal Justice Commons

\section{Recommended Citation}

Dickinson, Timothy, and Scott Jacques. 2019. Drug Sellers' Neutralizations of Guiltless Drug Sales and Avoidance of "Drug Dealer" Identities. International Journal of Drug Policy, 73:16-23.

This Article is brought to you for free and open access by the Department of Criminal Justice and Criminology at ScholarWorks @ Georgia State University. It has been accepted for inclusion in CJC Publications by an authorized administrator of ScholarWorks @ Georgia State University. For more information, please contact scholarworks@gsu.edu. 


\section{INTRODUCTION}

Since the publication of its original thesis about 60 years ago (Sykes and Matza 1957), neutralization theory has become one of the most "influential explanations of criminal behavior" (Maruna and Copes 2005: 3). Although originally proposed as an explanation for how conventionally-oriented juveniles commit crime, researchers have since used the theory to explore a diverse range of adult and juvenile offenses. These include violent crime (e.g., Agnew 1994), property crime (e.g., Copes 2003; Cromwell and Thurman 2003), white collar crime (e.g., Benson 1985; Stadler and Benson 2012), identity theft (e.g., Copes and Vieraitis 2009), sex crimes (e.g., DeYoung 1988; Scully and Marolla 1984), cybercrime (e.g., Holt and Copes 2010), and drug crime (e.g., Jacinto et al. 2008; Mohamed and Fritzvold 2010; Sandberg 2012).

Despite this attention, however, several conceptual and methodological issues remain underexplored. First, a small body of research examining occupational and corporate crime finds that offenders' sociodemographic characteristics and other attributes shape their neutralizations (e.g., Klenowski, Copes, and Mullins 2011; Stadler and Benson 2012), but questions remain as to whether this occurs in other crime types such as illicit drug sales. Second, previous research suggests that neutralizations are incorporated into offenders' narrative identities and may not be best captured through direct questions (Maruna and Copes 2005; Orbuch 1997). Yet, little research examines how offenders' neutralizations vary when they follow questions about guilt and when they are spontaneously incorporated into life stories (but see Maruna 2001). Finally, researchers note that persistent violent offenders use neutralizations despite exhibiting little or no guilt for their crimes (e.g., Jacobs and Copes 2015; Topalli 2005). Although some research has explored how illicit drug users neutralize their crimes (see, e.g., Coomber et al., 2016; Hathaway et al., 2011; Miller 2005; Sandberg 2012), what has been underexplored is whether and how 
persons who sell illicit drugs use neutralizations similarly to violent offenders due to a lack of guilty feelings concomitant with the moral ambiguity surrounding these crimes.

The present study addresses these gaps in the literature by examining neutralizations among active drug sellers. More specifically, we explore if drug sellers' ages and access to economic resources influence the types of neutralizations they use. We also investigate whether there are differences between the neutralizations they present when posed direct questions about guilt compared to those embedded in the storied selves they present over the course of their interviews. Finally, we examine if neutralizations are used by drug sellers who report not feeling guilty for their crimes, and, if so, what functions these neutralizations serve.

\section{Conceptual Background}

As originally proposed by Sykes and Matza (1957), neutralization theory posits that many delinquents do not hold subcultural value systems supporting criminal activity. Instead, they are at least "partially committed to the dominant social order" (Sykes and Matza 1957: 666), and, therefore, experience feelings of guilt when committing any acts that violate norms of this social order. To explain how delinquents initiate and continue criminal activity despite anticipated internal sanctions and disapproval from others, Sykes and Matza contend that they "neutralize" guilt and shame by justifying their actions in ways that are valid to them but not to "the legal system or society at large" (1957: 666). These neutralizations consist of consciously or subconsciously crafted explanations that an individual verbally gives to others or uses as part of an internal dialogue (Fritsche 2002; Maruna and Copes 2005; Murphy 2004). With neutralizations, delinquents avoid social censure and protect their self-images (Sykes and Matza 1957: 667). Although Sykes and Matza originally proposed the theory to explain juvenile 
delinquency, it has since been applied to a range of deviant and criminal adult behaviors (e.g., Benson 1985; Dabney 1995; Jacobs and Copes 2015; Scully and Marolla 1984).

Sykes and Matza (1957) argue neutralizations do not necessitate that one commits crime. They instead "make deviant behavior possible" (666) by discounting the anticipated internal or external sanctions that would otherwise prevent offenders from carrying out contemplated crimes. Matza (1964) describes this as "drift," or a "temporary period of irresponsibility or ... episodic relief from moral constraint" (Maruna and Copes 2005: 10). When one is in drift, contemplated crimes become viable courses of action. Although Sykes and Matza (1957) and Matza (1964) assert that delinquents use neutralizations before "primary deviance" (Lemert 1951), or offenders' first forays into a specific criminal activity, this contention has received limited empirical support (but see Agnew, 1994). This led researchers to suggest that neutralizations likely come after an initial offense and are a mechanism offenders use to assuage anticipated guilt and social sanctions before committing subsequent offenses (e.g., Hirschi 1969; Maruna and Copes, 2005; Minor 1984).

There are different types of neutralizations. Sykes and Matza (1957) provide a taxonomy consisting of five kinds: denial of responsibility, denial of injury, denial of victim, condemnation of condemners, and appeal to higher loyalties. With denial of responsibility, offenders attenuate social disapproval and feelings of personal failure by claiming their actions were accidental or caused by forces out of their control. Delinquents also avoid guilt by denying injury, or by recasting their actions as resulting in no harm. When denying victims, offenders neutralize sanctions by identifying their victims as deserving whatever harm was done to them or by claiming ignorance of who exactly they were harming. With condemnation of the condemners, offenders label the accusers as "hypocrites, deviants in disguise, or impelled by personal spite" 
and thus illegitimate (Sykes and Matza 1957: 668). And by appealing to higher loyalties, offenders rank non-legal morals, such as supporting a friend, as more important than following the law, should they be in conflict.

In the past decades, social scientists have greatly expanded this original list by adding neutralizations such as the defense of necessity (Minor 1981), the claim of normality (Coleman 2002), the metaphor of the ledger (Klockars 1974), justification by comparison, postponement (Cromwell and Thurman 2003), and the denial of criminal intent (Benson 1985), among others (for thorough lists see, Fritsche 2002; Schonbach 1990). Tedeschi and Reiss (1981) point out that the number of types of neutralizations is "theoretically unlimited" (Fritsche 2002: 375) because neutralizations are contextually specific. This is because neutralizations are based on "culturally embedded normative explanations" (Orbuch 1997: 460) for behavior and, as such, may vary according to what explanations are available to different ages, sexes, social classes, ethnic groups, and offending types (Sykes and Matza 1957: 669). One task for neutralization research, then, is to explore whether and how neutralizations vary with offender characteristics.

But, as Maruna and Copes (2005) propose, researchers examining neutralization theory should go beyond attempts to discover and label "new" techniques and sub-techniques of neutralizations, and also focus on the function of neutralizations. More specifically, they suggest that researchers should explore the use of "specific neutralizations" as a part of the "wider context of sense making that is the self-narrative process" (p. 64). This argument is based on Sykes and Matza's (1957: 670) original assertion that criminology needs to expand understanding of "the internal structure of techniques of neutralization as a system" and draws from a growing body of research highlighting the importance of narratives in offender identity- 
work and decision-making (e.g., XXXX, 2017; Maruna 2001; Presser 2008; Presser and Sandberg 2015; Sandberg 2010).

In short, that research argues that individuals' narratives - i.e., accounts of their life experiences and events (Ewick and Silbey 1995) - are vehicles by which they connect or disconnect their past actions to their present identities (McAdams 1990; Zerubavel 1998). In other words, people explain who they are to themselves and to other persons, and how their pasts connect to these identities by telling stories about their lives. Narratives are important because they not only describe past actions in light of present identity, but also because they determine what types of future behavior are acceptable (Bruner 1987; Frank 2010; Gergen and Gergen 1988; McAdams 1985).

The argument that neutralizations are part of a person's narrative identity suggests that prior work measuring neutralizations with distinct expressions or short vignettes describing neutralizing scenarios may fail to capture how some persons have incorporated neutralizations into their identities (Maruna and Copes 2005). Moreover, it is possible that the neutralizations presented by offenders when, one, asked about guilt or, two, asked to fit their experiences into short, distinct measures of neutralization suffer from threats to validity, due to testing effects and participants' needs to project social desirability. To date, little research has addressed this possibility by comparing and contrasting the neutralizations presented by offenders when directly asked about feelings of guilt to neutralizations incorporated in their narrative identities described during interviews or in situ.

As previously mentioned, neutralization theory, at least in its original form, hinges on the idea that offenders experience guilt when committing crime because they have internalized moral standards that disapprove of these crimes (Cromwell and Thurman 2003). This notion leads to 
the assumption that offenders who have not internalized these moral standards do not use neutralizations before or after committing offenses. Recent work, however, counters this assumption by noting that some offenders who do not experience guilt for their crimes still use neutralizations as tools to help them maintain positive self-images and social identities (see, e.g., Topalli 2005; Jacobs and Copes 2016). For instance, Topalli (2005) argues that "hardcore street offenders" do not neutralize feelings of guilt stemming from their crimes. They instead use them to blunt internal or external repercussions that may follow from showing mercy to victims or behaving in other "conventional" ways. This research suggests that neutralizations can be used by "individuals at any point" along a continuum of commitment to non-commitment to conventional values (Cromwell and Thurman 2003: 537; see also, Rosenfeld, Jacobs, and Wright 2003).

Research arguing that point is largely based on data gathered from offenders committing mala in se crimes: those widely regarded as invariably wrong, such as robbery and theft (see e.g., Agnew 1994; Copes 2003). Research among offenders committing mala prohibita crimes, or those not universally thought of as immoral, such as selling illicit drugs, has touched on the issue, albeit less so and with seemingly contradictory findings. For example, many illicit drug sellers neutralize their crimes with traditional neutralization techniques, like denial of injury and metaphor of the ledger (e.g., Coomber et al. 2016; Jacinto et al. 2008; Mohamed and Fritsvold 2010), but they also resist feeling guilty by not thinking of themselves as "drug dealers" (see also, Coomber et al. 2016; Potter 2009). If a person does not identify him or herself as committing a specific action or partaking in a particular role (defined by actions), it follows he or she may not experience any guilt for that action and therefore will not need to neutralize any guilt from it. 
Research among drug users from various contexts has found similar results. For instance, drawing from data collected from American, British and French cannabis users, Peretti-Watel (2003) argues that these users frame their consumption as a "risky" behavior and then deny the risk involved in ways conceptually similar to neutralizations. More specifically, they deny this risk by "scapegoating," or by distinguishing symbolic boundaries between their cannabis use the "risky" use of hard drugs by others. They also do so by positioning themselves as being able to “avoid or control risky situations" (Sandberg 2012: 374), what Peretti-Watel (2003) terms "selfconfidence." Finally, they deny risk by making "comparisons between risks," or by comparing their cannabis use to other, more widespread "risky" actions that many people take part in, such as alcohol use. Research among cannabis users in Denmark (Jarvinen and Demant 2011), Canada (Hathaway et al., 2011), and Norway (Sandberg 2012) and heroin users in Australia (Miller 2005) has found that these offenders also deny the risk in one or more of these ways when discussing their own illicit drug use.

Herein, we examine similar information from drug sellers we interviewed. Additionally, we go further than previous studies by exploring how these sellers expressions of guilt and use of neutralizations, plus their seeming lack of guilt and resistance of "drug dealer" identities, are all facets of the multi-layered systems of neutralizations that help them construct their self-views and avoid internal and external sanctions for their actions.

\section{DATA AND METHODS}

The data informing the present study were gathered through semi-structured interviews with two samples of unincarcerated, illicit drug sellers. All participants had been involved in the sale of illicit drugs within two years of being interviewed. The first sample consists of 33 
individuals from the St. Louis, Missouri metropolitan area. These individuals were located, recruited, and interviewed by the lead author in 2012. The second sample consists of 30 individuals from suburban Atlanta, Georgia. These individuals were located, recruited, and interviewed by the second author in 2004 and 2005. To be included in the St. Louis sample, informants had to meet one criterion: to have sold illicit drugs sometime in the year prior. To meet the sampling criteria for the Atlanta sample informants had to 1) be between the ages of 18 and 23 at the time of data collection; 2) have grown up in a middle-class, suburban community; and 3 ) have sold illicit drugs in the 2 years prior.

Both samples were accrued using snowball sampling strategies (Wright et al., 1992). We approached individuals we knew to formerly or actively be selling illicit drugs. We knew these individuals through school, work, and other social networks. We asked them if they would let us interview them about their involvement in selling drugs and to refer other individuals that met the study criteria. The St. Louis participants sold a range of illicit substances, including cocaine, crack-cocaine, crystal methamphetamine (meth), DMT, hallucinogenic mushrooms, heroin, ketamine, LSD (acid), marijuana, MDA (sassafras), MDMA (ecstasy, molly), nitrous oxide, and various pharmaceuticals. The Atlanta participants sold cocaine, ecstasy, LSD, mushrooms, and pharmaceuticals. All dealers sold in "closed" markets, meaning within networks of preexisting ties (May and Hough 2001: 139). However, 8 of the St. Louis participants also sold in "semiopen" markets wherein they made exchanges with strangers, provided they "looked the part" (May and Hough 2004: 553).

The St. Louis and Atlanta sellers ranged in age, respectively, from 19 to 41 and 18 to 23. Twenty-seven participants in the St. Louis sample were White, three were African-American, two were Latino, and one was Chinese-American. All Atlanta sellers were White, except for one 
who was part Asian, part White. Both samples were predominantly male, with the St. Louis sample including 3 females and the Atlanta sample including 2. At the time of data collection, 16 of the St. Louis sellers had graduated college or were attending college classes, 6 had graduated high school, 4 held General Educational Development (GED) degrees, and 3 dropped out of high school. Some of the informants in the Atlanta sample had graduated college, most were attending college, and all had a high school diploma or equivalent.

Six of the St. Louis sellers had spent time incarcerated for drug sales, 15 had been convicted of sales or possession but had not been incarcerated, 3 had been incarcerated for other offenses, and 10 had never been arrested for any crimes. Among the Atlanta sellers, only a few had been arrested, with no case leading to incarceration (for details, see XXXX 2015). Most of the St. Louis sample were employed at the time of the interview, with only four relying solely on drug sales to support themselves financially. Unfortunately, employment was not consistently discussed with the Atlanta sellers, so no data on this issue are provided here.

Unlike the Atlanta sample, which was comprised entirely of middle-class sellers, the St. Louis sample includes 4 individuals from disadvantaged urban neighborhoods, 2 from working class urban neighborhoods, 25 from working-class to lower-middle-class suburban neighborhoods, and 2 from working-class rural neighborhoods. We determined the informants' classes on the basis of their own descriptions of the communities and the occupation and educational attainment of their parents.

Similar methods were used to collect data from sellers in both samples. After approaching possible participants, both authors explained the safeguards in their respective studies (e.g., using pseudonyms in place of real names, storing interviews and transcriptions on encrypted flash drives, etc.; see XXXX 2017; XXXX 2008). After gaining voluntary consent 
from participants, the authors interviewed them using semi-structured interview guides. These interviews ranged from 30 minutes to 2 hours long. They were all conducted in an informal manner intended to mimic free-flowing, "normal" conversation. This allowed informants to expand on tangential narratives and the authors to probe informants' responses for further detail and clarification. Due to this structure and the distinct research focuses of the authors, not all informants were asked the same questions or in the same order. Nonetheless, both projects focused on elements of the sellers' careers, their identities as drug sellers, and how they managed any guilt from selling drugs.

Data about whether and how the sellers accounted for their involvement in selling drugs were gathered from the St. Louis sample with the question, "How do you feel about selling drugs?" Atlanta sellers were asked, "Do you feel guilty about dealing drugs?" Additional data were gathered from the informants' responses to various other questions and probes that explicitly or implicitly referred to their feelings about selling drugs, their identities as "drug dealers," and how they managed conflict with others.

Data were analyzed using NVivo 10 as an organizational tool. We first compared the sellers' statements within their own interviews and then with the interviews of the other sellers. Statements that were thematically similar were grouped into broad domains (e.g., sellers that feel guilty, sellers that do not feel guilty, etc). These domains were then further classified by separating them into more specific subdomains (e.g., sellers that feel guilty for breaking the law, sellers that feel guilty for taking risks, etc.) (Spradley 1979, 1980). We examined these domains and subdomains for thematic patterns regarding the informants' use of neutralizations, the content of these neutralizations, and the informants' presentations of their identities. Throughout analysis, themes that were countered were discarded or altered (Charmaz 2006; Maruna 2001). 
The results are comprised of the prominent themes that arose across the informants' interviews. It should be noted that the themes presented herein represent the results drawn from this specific group of illicit drug sellers and therefore may not reflect the parameters of the population of drug sellers writ large.

\section{FINDINGS}

\section{Guilty Feelings}

For members of both samples, it was rare for sellers of soft drugs, such as LSD, marijuana, and mushrooms, to explicitly or implicitly express guilt about the actual act of selling illicit drugs. For example, Justin said, "I don't believe what I am doing is wrong." Richard echoed this sentiment, albeit with more emphasis, "Hell no! There ain't no guilt in it man. I don't do nothing bad." However, the sellers of hard drugs, such as crack cocaine, heroin, and meth, in the St. Louis sample did express feelings of guilt about the harmful effects these drugs could have on their customers. Snap, for instance, commented:

I was selling meth, I was getting ice [high quality crystal methamphetamine] from Mexico, which is like top of the line, and then I was getting sassafras [MDA]. I started mixing 'em together, and it was just all bad, and I turned into a bad person. The people I was selling it to were just like tweaked out on top of it ... I still have a lot of fucked up feelings about what I used to do ... after what it did to me, being on speed, what it did to my people, it's fucked up.

V expressed similar feelings, remarking:

I've had people do worse than beg me ... [W] hen people are trying to get drugs ... you really see a part of humanity that's like, you're not supposed to see. ... [T] hat shit fucked my head up.... [W] hen you see somebody fucking begging you for drugs, the kinds of shit that they will fucking give you or offer you, is just fucking disturbing dude.

While most sellers that distributed soft drugs did not view exchanging drugs for money as wrong in itself, participants did feel guilty for potential knock-on effects. Paramount among 
these, especially for the Atlanta sellers - who recall were young and middle-class - was disappointing their parents. Pete spoke about this issue:

I didn't want my parents to think that I was selling drugs. I didn't want them to be disappointed in me. It's just the concept of "He's a drug dealer," you know. All these women say, "Oh, he's a drug dealer, he's a drug dealer, scum of the earth," like that's the fucking title given to drug dealers, and I didn't want to be that and I didn't want anybody to know that's what I was. I didn't think that I was [a bad person]. I still don't think I was for selling weed. I wasn't a bad person. Yeah, I sold drugs that were illegal-I mean I don't think they should be illegal, but that's not what it's about.

Though these sellers did not adopt what they perceived to be their parents' normative stances on selling illicit drugs, it was important to not disappoint them (see XXXX 2015). Thus, these sellers felt guilty about selling drugs because it went against their parents' expectations. This guilt also relates to the possibility that their parents would think less of them for risking involvement with the criminal justice system and jeopardizing their academic and occupational futures. In a word, Pete felt guilty about being labeled an "idiot" by his parents.

Further to that point, sellers from both cities internalized norms prohibiting "stupid" (Phillip) actions that could end in legal consequences, such as selling illicit drugs, and indicated they felt guilty for this reason. "Man, this is stupid," Joe stressed, speaking of his own involvement in selling drugs, "If I get caught with any of this shit, I'm fucked." William felt similarly about selling drugs while on community supervision for a drug charge. He succinctly commented, "Yeah, selling drugs on probation [isn't] smart." V followed suit, emphasizing that selling meth was "fucking retarded." Referring to why he quit selling, Christian, stated:

I remember thinking to myself, "I'm going to [college] and I'm not going to make enough money to make it worth basically fucking up your life and not being able to go to [college]." Cause it was basically like I was on the right track and I was done with high school and it was finally time for me to go off and make something of myself, and I just knew that if I was going to continue to deal, I was going to put that at a heavy risk and it just wasn't worth it. I mean having the money was nice, but the rest of my life wasn't worth the money. The chance of getting caught wasn't worth it compared to any of the positives. 
Here, again, it is not that these sellers feel guilty about selling drugs. They do, however, feel guilty about acting in ways they consider to be "stupid." In order to maintain positive selfimages, they neutralized this "stupid" behavior.

\section{Question-Based Neutralizations}

When asked directly about feelings of guilt, participants offered several neutralizations to rationalize selling illicit drugs. Because these techniques are contextually specific (see Tedeschi and Reiss 1981), we present them as used by the sellers and do not fit them into existing typologies (e.g., Cromwell and Thurman 2003; Stadler and Benson 2012; Sykes and Matza 1957). We do so because our goal is not to "identify the dynamics of account giving inherent to all contexts" (Fritsche, 2002: 375). Rather, we seek to, one, present a micro-taxonomy of the different neutralizations used by illicit drug sellers with varying characteristics, and, two, explore how these neutralizations are incorporated into their identities as drug sellers.

One way that sellers neutralized guilty feelings about selling drugs was by claiming they did so out of necessity (see Minor, 1981 on the "defense of necessity"). This neutralization was used exclusively by the older, less affluent sellers from St. Louis. For instance, when asked why he sold drugs despite the risks, Gregory replied, “I don't like it. I feel like I am forced to ... 'cause of the economy ... [The] hundred, two hundred bucks I make helps me ... pay my rent [and] ... helps me eat." Likewise, John, answered the same question thusly:

It makes me feel like I got fucking money to pay my bills ... [I]t feels like a necessity, a survival strategy if you will ... No one wants to live like that ... I've always done it to support myself ... I don't feel like it's a choice sometimes. It's like, "Well fuck, I gotta pay a bill, or I gotta do this or I gotta do that, so I mean I need some money." ... If I could make legitimate, legal money, I wouldn't have a reason to [sell drugs]. 
Like John, other participants emphasized that they lacked legal means for satisfying their basic needs. "I don't have a college degree, I don't have any fucking skill," V stressed, “[I'm] over here making minimum wage ... [I]t's hard to give that [selling drugs] up ... I always go back to it when times get hard." Burt explained, "I wish I had the education to be able to go out ... and get the good paying job ... [B]ut I wasn't dealt those cards, ... so I try to make the best of it ... [Y]ou gotta do what you gotta do.”

Another neutralization, proffered by sellers in both samples, was to deny that their business harmed anyone (see Sykes and Matza, 1957 on "denial of injury"; c.f., Peretti-Watel, 2003: 29). This argument typically centered on the notion that they did not "force" customers to buy drugs, but, instead, were "helping" them get something they wanted. "I wasn't forcing people to buy it," Frank emphasized, "they were calling me." Dave reflected, "I don't understand why I should feel guilty ... I mean, basically I'm doing something to help somebody else out ... I don't see how I'm hurting somebody."

This neutralization was not unique to the sellers of soft drugs. On the one hand, hard drug sellers voiced awareness - and sometimes guilt - that their products (crack, heroin, or methamphetamine) are physically, mentally, and socially harmful for customers. Yet some of these sellers dodged consequent guilt by emphasizing that clients were choosing to be harmed, another neutralization technique. Consider the orientation of Jarod, who cooked and supplied methamphetamine in addition to selling heroin:

I didn't really feel bad about it 'cause I wasn't pushing my product on kids. I wasn't pushing my product on anybody that didn't want to do it, and everybody that touched my shit was of grown age, and was an adult and they made their own decisions. ... God gave us all free will. I didn't force anybody to do anything. Everybody came to me.

The sellers that trafficked predominantly in hallucinogens and marijuana further neutralized guilty feelings by arguing that their wares provided customers with physical and 
spiritual benefits (see Friedman 1974 on "the claim of benefit"). John stressed that by selling customers mushrooms, he was helping them "see God.” Referring to selling marijuana, Tom said, "There's nothing really to feel guilty about. [I'm] just selling somebody something that can help them relieve stress, chill out, and get away from their paranoid, stressful life, whatever it is: school, parents, whatever.” Another marijuana dealer, Natalie, remarked:

Actually, the reason [I feel good about selling] is I've got people that depend on me for it. My dad, for instance, is a diabetic. He has neuropathy really bad, and so I give him marijuana weekly to use for medicine. ... [I]t just kills me that people can see me as a criminal. ... I [help] a lot of people. ... [Another] girl ... uses it for her ADHD. [S] he says it helps her quite a bit. ... I have some friends that say it helps with their anxiety ... And that's another thing: It's not like these are people I don't give a shit about. These are people that I genuinely care about. ... I feel like I'm kind of being ... a caretaker.

When directly asked about feelings of guilt, marijuana sellers in both samples also highlighted the shifting legality of this drug in the United States. These sellers referenced the growing number of US states permitting medicinal and recreational marijuana as evidence of a large number of others approving of its use and sale. This, in turn, promoted their own stances on it not being "wrong" (see Coleman 2002 on "everybody does it"). "There's a fundamental argument that I have that I don't agree that pot should be illegal," Justin B said, "so much of the percentage of the United States is down with smoking pot.” Brian expressed a similar view, "We're basically bootleggers ... One day we'll look back at this and think of it as the Prohibition era." Allen also referenced the temporary illegality of alcohol in the US: "I'm in the Prohibition era of marijuana. It's only a matter of time until it's legal."

\section{Narrative-Based Neutralizations}

In addition to proffering neutralizations subsequent to being asked about guilt, the sellers also did so spontaneously throughout the stories they told about themselves. Aside from those 
that trafficked in large amounts of hard drugs, participants positioned themselves as not being "drug dealers" in their stories. In these narratives, the sellers are not, as in the prior section, assuaging feelings of guilt by altering their perspectives on motives for or outcomes of selling. They are instead preempting any potential feelings of guilt by altering their perspectives on who they are and what they are doing. Put differently, here the sellers avoided feelings of guilt by incorporating neutralizations into their self-identities.

To do so, the St. Louis and Atlanta sellers continually referenced symbolic boundaries (Lamont and Molnar 2002) conceptually separating themselves from persons who sell drugs and should feel guilt, with these two traits defining - in their minds - a (bad) "drug dealer." While an outsider may categorize any person selling illicit drugs as a "drug dealer" and hence an immoral criminal, these sellers distinguished themselves as different from "drug dealers" on the basis that their actions are not worthy of guilty feelings (see Cromwell and Thurman 2003 on "justification by comparison"; see also, Benson 1985, Coomber et al., 2016). Ergo, they did not need to take measures to ameliorate feelings of guilt.

Sellers drew the line between themselves and drug dealers in a few ways. One was to emphasize that they, unlike "drug dealers," did not sell dangerous drugs (see also, Jarvinen and Demant 2011; Sandberg 2012). "I don't even consider myself as even in the same ballpark as a cocaine dealer or a meth dealer or a heroin dealer," Allen said, "I'm just completely different." "Meth can blow up a house," Julie emphasized, "heroin just gets people too addicted and they overdose all the time, try to kill people for it. Same with crack, [people] do stupid stuff for it." Because they did not consider themselves as selling drugs that harm others, they did not identify as "drug dealers" and, therefore, did not consider themselves as committing immoral actions. 
Another point of differentiation was refraining from predatory and violent behavior, for which the notion of a "drug dealer" is notorious (see Goldstein 1985). For instance, many of the sellers consistently described their actions as just "helping" friends and claimed that they were not "drug dealers" for that reason. When asked to define what a "drug dealer" was then, many replied like Gregory. He stated, "A drug dealer is [someone] that is out there jacking [robbing] people ... and [has] a gun." The participants often referenced this conceptualization of a "drug dealer" — and contrasted themselves against it—when talking about conflict. Natalie was one of these sellers. When describing a conflict with a customer who was late on a drug debt she referred to herself as "not your normal like drug dealing guy" because she did not see the need to use "violence" when responding. She continued, "The last thing I want is problems and violence and just drama and all ... [I]t's not like I'm gonna shoot the guy over something." Robert similarly described his response to $\$ 360$ of drug money being stolen from his car while at work:

Fucking nothing. I mean what am I gonna go do-shoot him? It's not worth getting in trouble over. The only thing I could have done is went and whupped his ass, and at that point it wasn't worth getting in trouble, because I was trying to sell and make a little money, but I'm not trying to escalate in criminal activities.

At first glance, the neutralizations embedded in the sellers' stories may seem conceptually similar to those given following direct questions as both types could ameliorate any negative feelings the sellers may have experienced as a result of selling illicit drugs. But it is important to consider that the sellers only emphasized that they were not "bad drug dealers" in their stories and none did so in response to the direct questions. This suggests that the two types of neutralizations — question driven and narrative based — should be considered as conceptually distinct. To explain further, the neutralizations the sellers gave in response to our questions likely stemmed from the sellers being reminded that they could be considered "drug dealers" because 
they traded illicit drugs for money. In effect, our questions "altercasted" the informants into identities as "drug dealers" (see Weinstein and Deutschberger 1963 on "altercasting”). They then consciously crafted statements in response to the possible negative implications of this identification. The neutralizations embedded in their stories, on the other hand, were likely not consciously crafted. Recall that the stories people tell about themselves represent how they like to view themselves and their actions (Frank 2010; McAdams 1985, 1990). When describing themselves and their day-to-day lives, the sellers made no explicit or implicit indications of taking conscious steps to avoid thinking of themselves as "drug dealers." They just did not do so. This suggests that they did not view themselves as persons who should question whether their actions were guilt-worthy. This then preempted any need to neutralize in the first place. Following this line of reason, the two types of neutralizations used by these sellers can be conceptually distinguished because question-based neutralizations represent sellers' conscious efforts to avoid negative sanctions following identification as immoral actors, while narrativebased neutralizations are incorporated into their identities and thus help them avoid questioning whether they should feel guilty in the first place.

\section{DISCUSSION}

This paper's goal is to explore neutralizations among illicit drug sellers. Seldom did our participants indicate feelings of guilt for the actual act of selling drugs. Younger sellers of soft drugs, however, expressed feelings of guilt associated with potentially disappointing their parents. Hard drug sellers referred to feeling guilty about the harmful effects their wares could have on their customers. Another commonality among respondents was guilty feelings stemming from risking legal consequences. When directly asked about feelings of guilt, sellers offered 
several types of neutralizations to explain their actions. The older, less affluent sellers from St. Louis neutralized potential sanctions stemming from their behavior by claiming it was out of necessity. In addition, they, and the sellers from Atlanta, explained a lack of guilt by arguing that they did not harm their "victims" because these individuals willingly bought drugs, and may benefit from them. Moreover, throughout interviews, sellers constructed identities as not (bad) "drug dealers," and thereby preempted any potential feelings of guilt that could potentially arise from thinking of themselves as such.

These findings show that persons committing similar offenses may proffer different neutralizations associated with sociodemographic differences. When asked about their feelings of guilt, the older, less affluent sellers commonly justified their actions to the interviewer by arguing that they sold drugs out of necessity. This neutralization was not used by any of the younger, more affluent sellers. This is likely due to the different "background expectancies" of the two groups. Background expectancies refer to a social group's collective understanding of the ways norm violations "should" be explained in order for its members to understand and accept these explanations (Blumstein et al. 1974; Goffman 1967; Scott and Lyman 1968; see also, Mills 1940). These background expectancies, in turn, are shaped by the group's social structural position (Minor 1981; Presser 2009). That is, whether neutralizations are acceptable depends on if they "make sense" given the resources available to the individual giving them and the group they are given in. In this case, the defense of necessity was not available to the younger, more affluent sellers because they had all their material needs met by their parents (see XXXX, 2015). This was unlike the older, less affluent sellers whom did not live at home and could not rely on financial assistance from their parents. For the younger, more affluent sellers, arguing that they did not feel guilty because they sold drugs out of financial need would not 
make sense to themselves nor to the interviewer. This suggests that differential access to resources explains, in part, why some young offenders may rationalize their behavior differently - and have different cognitive patterns more broadly - than older, long-term offenders (see Gibbs, Potter, and Goldstein 1995; Maruna and Copes 2005; Moffitt 1993). The finding also highlights that social structural context can influence the use of neutralizations among some offenders (see Orbuch 1997).

Some participants offered multiple neutralizations for their actions when explicitly asked about their feelings of guilt. For example, they justified selling drugs by claiming it was out of necessity and did not harm customers. Furthermore, when analyzing the sellers' interviews in their entirety, we found that sellers preemptively neutralized possible feelings of guilt by presenting narrative identities as contra that of a "drug dealer." This suggests that the act of neutralizing fallout from immoral actions is not always a static, monothematic technique, as often treated in criminological research (see Maruna and Copes 2005: 32). Neutralizations and other forms of identity management, such as the creation of symbolic boundaries, are instead complex, active, interactional processes that occur when persons are making sense of who they are and what they are doing.

Identity can be conceptualized as how individuals view themselves and the kind of persons they like to think of themselves as being (Brookman, Copes, and Hochstetler 2011; Hogg and Abrams 1988; McCall and Simmons 1966; Shover 1996). Identity is important because it lays a template for how an individual should behave (Stets and Burke 2000). But an individuals' identity has a reciprocal relationship with his or her behavior, as the responses the individual receives (from him or herself or others) due to this behavior can then reshape the individual's self-view (Goffman 1957, 1971; Hogg, Terry, and White 1995). Put simply, if you 
view yourself as a moral person and then you or others negatively respond to your immoral actions, this may cause you to reconsider whether you are in fact a moral person. The present study suggests that neutralizations may play a role in this process of identification and reidentification.

Many of the sellers interviewed did not view themselves as "drug dealers." This was indicated by the absence of references to themselves as such within their stories (Frank 2010; McAdams 1985, 1990). Not thinking of themselves as "drug dealers" in the first place, then, was a subtle neutralization that comprised part of their identities. But when we questioned them about guilt or, in other words, when we responded to these projected identities, they may have been forced to reconsider these identities in light of how we potentially identified them — as "drug dealers." The sellers then utilized more overt neutralizations as a means to maintain positive selfidentities in the face of this potential re-identification and its attendant negative repercussions (i.e., guilt or shame). Following this, it is possible that the sellers then incorporated these new neutralizations into their identities when moving forward. Thus, neutralizations may not just be a rationalization created at one point in time with a temporally limited effect but may comprise part of individuals' identities and therefore have on-going influence on the shape of these identities over time. Moreover, the ways in which individuals may neutralize their actions, or their systems of neutralizations, may be multi-layered and consist of subtle neutralizations within their identities and overt neutralizations consciously proffered to themselves and others.

That the drug sellers implicitly contrasted themselves against others they considered to be "real" drug dealers may reflect arguments advanced by a recent body of research devoted to exploring the "normalization" of drug use and its effect on how drug users "drift" (Matza, 1964) into the roles of social suppliers (e.g., Coomber et al. 2016). In short, this research argues that 
drug use, particularly the use of cannabis and other soft drugs, has become normalized, or has moved from the margins of moral acceptability to its center among many individuals (see Hathaway 2004; Parker et al., 1998; Parker et al., 2002; Shiner and Newburn, 1997). Coomber and colleagues (2016) argue that this, in turn, has created a context in which individuals who are ostensibly "dealing drugs" by obtaining drugs and distributing them to others do not see themselves as "drug dealers" because they consider these actions as but small steps away from the morally acceptable use of drugs.

Like the subjects studied by Coomber and colleagues, it is possible that many of our informants, particularly those trafficking in marijuana and other soft drugs, also spend much of their time in contexts wherein the use and sale of drugs has become normalized. This may contribute to them not seeing themselves as "drug dealers" when in these contexts. In other words, this contextual normalization may have eased their drift into roles as "drug dealers" and thus contributed to their lack of identification as such. But when interviewed, the informants were taken out of these contexts and placed in one (i.e., one with an outside, academic interviewer) wherein the use of drugs, let alone the distribution thereof, was no longer normalized. They may have therefore considered their actions in a new contextual light that called attention to their drift into selling that had formally occurred subtly and without their attention. This awareness, in turn, may have engendered a cognitive dissonance (see Festinger 1962) within them by highlighting that they were in fact "drug dealers," at least in the eyes of some. They then may have created the neutralizations provided to us as a means to manage this dissonance. In a way then, it is possible that the interview setting itself was partially responsible for the creation of some of the informants' neutralizations. 
The sellers that sold hard drugs did not tell stories about themselves wherein they were not positioned as "drug dealers" like the other drug sellers did. This suggests that they did in fact think of themselves as such. But given that thinking one is not a "drug dealer" may preemptively help a person avoid negative feelings, why did these sellers not construct identities as persons who were not "drug dealers" then? The possible answer to this can be drawn from both the research on normalization previously discussed as well as recent work on symbolic boundary making by drug users and dealers conducted by Copes and colleagues (e.g., Copes 2016; Copes et al., 2016; Copes et al., 2008; Copes et al., 2018; Webb et al., 2017). In short, this research argues that hard drug users and sellers operate in a broader cultural context in which many persons identify them as participating in risky and self-damaging behavior. In other words, mainstream, conventional culture symbolically distinguishes them as different because of the types of drugs they use and traffic in. To avoid this stigmatization, and thereby maintain positive self-images, these users and dealers make conceptual distinctions between their own use and associated behavior and that of other users and dealers who they consider to be unsavory or deviant.

The hard drug sellers that we interviewed also operated in a cultural context that symbolically separated hard drug users and sellers from the rest of the population. Unlike the soft drug sellers, whose drift into selling could have been facilitated by the normalization of soft drug use and sales, the hard drug sellers could not so easily drift into hard drug sales. They instead had to cross a distinct symbolic boundary and this, in turn, may have compelled them to adopt the identity of "drug dealer." This suggests that the symbolic boundaries associated with certain drug types may play a role in the types of neutralizations available to specific drug sellers. Not assigning oneself an identity as a "drug dealer" - and thus preemptively preventing the need to 
neutralize one's crimes - may simply not be an option for the individuals selling hard drugs because of the symbolic boundaries associated with these drugs, whereas those selling soft drugs may be able to neutralize their crimes in these ways because the boundary between soft drug use and sales and morally acceptable behavior has become blurred.

In closing, the present study has methodological implications for researching neutralizations among drug sellers. The findings suggest that prior research using direct, standardized questions and the presentation of abstract vignettes may fail to capture a sizeable part of the neutralization process among these offenders (Maruna and Copes 2005). As Veroff and colleagues (1993: 439) argue, "direct questions can elicit historical truth to some extent, but they often engage much more of the person's social self-presentation." Research relying solely on responses to such measures hazard conflating participants' views on what others find socially desirable with the participants' personal views on moral behavior and the ways in which they neutralize moral transgressions. Likewise, studies exploring neutralization through the presentation of abstract vignettes may be capturing respondents' views on social desirability and their understanding of the "universal accounts" for certain behaviors, rather than how these respondents have incorporated neutralizations into their own storied identities (see also, Maruna and Copes 2005).

Our study is not without its own limitations, of course. Key among these is its reliance on cross-sectional data. Like many other explorations of neutralization theory (e.g., Benson 1985; Copes 2003; Jacobs and Copes 2015; Topalli 2005), this aspect of our study design precludes us from untangling the sequential relationships between the sellers' neutralizations, their efforts at identity-maintenance, and their offending. To order these relationships, future research should employ longitudinal research designs. By collecting data at two or more points in time from the 
same informants, researchers will be able to determine if drug sellers construct identities counter to that of "drug dealer" prior to using neutralizations when identified as such by others or if they use neutralizations and then construct these identities. A smattering of longitudinal studies have been conducted examining neutralization theory (see, e.g., Agnew 1994; Higgins, Wolfe, and Marcum 2008; Minor 1981; Shield and Whitehall 1994), but these studies largely rely on survey measures and, as such, may have failed to fully capture the "system" of neutralizations incorporated into offenders' identities. Future research should follow suit with these designs and collect data over time but do so by conducting in-depth interviews with offenders and others. This design would allow researchers to temporally order offenders' neutralizations, identitymanagement, and offending while also addressing the shortcoming of only drawing information about these domains from survey questions, vignettes, and direct interview questions.

\section{REFERENCES}

Agnew, R. (1994). The Techniques of Neutralization and Violence. Criminology 32: 555-580.

Benson, Michael L. (1985). Denying the Guilty Mind: Accounting for Involvement in a WhiteCollar Crime. Criminology 23: 583-607.

Blumstein, P.W., Carssow, K.G., Hall, J., Hawkins, B., Hoffman, R., Ishem, E., Maurer, C.P., Spens, D., Taylor, J. and Zimmerman, D.L. (1974). The Honoring of Accounts. American Sociological Review, 39: 551-566.

Brookman, F., Copes, H., and Hochstetler, A. (2011). Street codes as formula stories: How inmates recount violence. Journal of Contemporary Ethnography 40:397-424.

Bruner, J. (1987). Life as narrative. Social Research 54: 11-32 
Charmaz, K. (2006). Constructing Grounded Theory: A Practical Guide through Qualitative Analysis. Sage.

Coleman, J. W. (2002). The Criminal Elite: The Sociology of White-Collar Crime. 5th ed. St. Martin's.

Coomber, R., Moyle, L., and South, N. (2016). The normalisation of drug supply: The social supply of drugs as the "other side" of the history of normalisation. Drugs: Education, Prevention and Policy, 23(3), 255-263.

Copes, H. (2003). Societal Attachments, Offending Frequency, and Techniques of Neutralization. Deviant Behavior 24: 101-127.

Copes, H. (2016). A narrative approach to studying symbolic boundaries among drug users: A qualitative meta-synthesis. Crime Media Culture 12:193-213.

Copes, H., Hochstetler, A., and Williams, J. P. (2008). "We weren't like no regular dope fiends": Negotiating hustler and crackhead identities. Social Problems 55:254-270.

Copes, H., Tchoula, W., Kim, J., and Ragland, J. (2018). Symbolic perceptions of methamphetamine: Differentiating between ice and shake. International Journal of Drug Policy, 51, 87-94.

Copes, H. and Vieraitis, L.M., (2009). Bounded Rationality of Identity Thieves: Using OffenderBased Research to Inform Policy. Criminology \& Public Policy, 8(2): 237-262.

Cromwell, P. and Thurman, Q., (2003). The Devil Made Me Do It: Use of Neutralizations by Shoplifters. Deviant Behavior, 24(6): 535-550.

Dabney, D. (1995). Neutralization and Deviance in the Workplace: Theft of Supplies and Medicines by Hospital Nurses. Deviant Behavior, 16(4): 313-331. 
DeYoung, M. (1988). The Indignant Page: Techniques of Neutralization in the Publications of Pedophile Organizations. Child Abuse and Neglect, 12: 583-591.

Ewick, P., and Silbey, S. S. (1995). Subversive Stories and Hegemonic Tales: Toward a Sociology of Narrative. Law and Society Review: 197-226.

Felson, R. B. (1982). Impression Management and the Escalation of Aggression and Violence. Social Psychology Quarterly, 45(4): 245-254.

Festinger, L. (1962). A Theory of Cognitive Dissonance, vol. 2. Stanford University Press. Frank, A. W. (2010). Letting Stories Breathe: A Socio-Narratology. University of Chicago Press.

Friedman, N. L. (1974). Cookies and Contests: Notes on Ordinary Occupational Deviance and Its Neutralization. Sociological Symposium 11:1-9.

Fritsche, I. (2002). Account Strategies for the Violation of Social Norms: Integration and Extension of Sociological and Social Psychological Typologies. Journal for the Theory of Social Behaviour 32: 371-394.

Gergen, K. J., and Gergen. M. M. (1988). Narrative and the Self as Relationship. Advances in Experimental Social Psychology 21: 17-56.

Gibbs, J. C., Potter, G. B., and Goldstein, A. P. (1995). The EQUIP Program: Teaching Youth to Think and Act Responsibly through a Peer-Helping Approach. Research Press.

Goffman, E. (1959). The Presentation of Self in Everyday Life. New York, NY: Anchor Books. Goffman, E. (1967). Interaction Ritual: Essays in Face-to-Face Behavior. Aldine Publishing Company.

Goffman, E. (1971). Relations in Public: Microstudies of the Public Order. New York, NY: Basic Books, Inc., Publishers.

Hathaway, A. D. (2004). Cannabis users' informal rules for managing stigma and risk. Deviant behavior, 25(6), 559-577. 
Hathaway, A. D., Comeau, N. C., \& Erickson, P. G. (2011). Cannabis normalization and stigma: Contemporary practices of moral regulation. Criminology \& Criminal Justice, 11(5), 451-469.

Higgins, G.E., Wolfe, S.E. and Marcum, C.D. (2008). Music Piracy and Neutralization: A Preliminary Trajectory Analysis from Short-Term Longitudinal Data. International Journal of Cyber Criminology, 2(2): 324-336.

Hirschi, Travis. (1969). Causes of Delinquency. University of California Press.

Hogg, M. A., and Abrams, D. (1988). Social Identifications: A Social Psychology of Intergroup Relations and Group Processes. London, UK: Routledge.

Hogg, M. A., Terry, D. J., and White, K. M. (1995). A Tale of Two Theories: A Critical Comparison of Identity Theory with Social Identity Theory. Social Psychology Quarterly 58: $255-69$.

Holt, T. J., \& Copes, H. (2010). Transferring Subcultural Knowledge Online: Practices and Beliefs of Persistent Digital Pirates. Deviant Behavior, 31: 625-654.

Jacinto, C., Duterte, M., Sales, P., and Murphy, S. (2008). “I'm Not a Real Dealer": The Identity Process of Ecstasy Sellers. Journal of Drug Issues, 38(2): 419-444.

Jacobs, B.A. and Copes, H. (2014). Neutralization without Drift: Criminal Commitment among Persistent Offenders. British Journal of Criminology, 55(2): 286-302.

Järvinen, M., \& Demant, J. (2011). The normalisation of cannabis use among young people: Symbolic boundary work in focus groups. Health, risk \& society, 13(2), 165-182.

Klenowski, P.M. (2012). "Learning the Good With the Bad": Are Occupational White-Collar Offenders Taught How to Neutralize Their Crimes? Criminal Justice Review, 37(4): 461477.

Klockars, C.B. (1974). The Professional Fence. Free Press. 
Lamont, M., and Molnár, V. (2002). The Study of Boundaries in the Social Sciences. Annual Review of Sociology 28: 167-195.

Lemert, E. M. (1951). Social Pathology. McGraw-Hill.

Maruna, S. (2001). Making Good: How Ex-Convicts Reform and Rebuild Their Lives. American Psychological Association.

Maruna, S., and Copes, H. (2005). Excuses, Excuses: What Have We Learned from Five Decades of Neutralization Research? Crime and Justice 32: 221-320.

Matza, D. (1964). Delinquency and Drift. Wiley.

May, T., and Hough, M. (2001). Illegal Dealings: The Impact of Low-Level Police Enforcement on Drug Markets. European Journal on Criminal Policy and Research 9: 137-162.

May, T., and Hough, M. (2004). Drug Markets and Distribution Systems. Addiction Research and Theory 12: 549-563.

McAdams, Dan P. (1985). Power, Intimacy and the Life Story: Personological Inquiries into Identity. Guilford.

McAdams, D. P. (1990). Unity and Purpose in Human Lives: The Emergence of Identity as a Life Story, in A. Rabin, ed, Studying Persons and Lives. Springer Publishing Company.

McCall, G. J., and Simmons, J. L. (1966). Identities and interactions. New York: Free Press.

Miller, P. G. (2005). Scapegoating, self-confidence and risk comparison: The functionality of risk neutralisation and lay epidemiology by injecting drug users. International Journal of Drug Policy, 16(4), 246-253.

Mills, C. W. (1940). Situated actions and vocabularies of motive. American Sociological Review, 5: 904-913.

Minor, W.W. (1981). Techniques of neutralization: A reconceptualization and empirical 
examination. Journal of Research in Crime and Delinquency, 18: 295-318.

Moffitt, T. E. (1993). Adolescence-Limited and Life-Course-Persistent Antisocial Behavior: A Developmental Taxonomy. Psychological Review 100: 674-701.

Mohamed, A. R., and Fritsvold, E. (2010). Dorm Room Dealers: Drugs and the Privileges of Race and Class. Lynne Rienner Publishers.

Murphy, E. (2004). Anticipatory Accounts. Symbolic Interaction, 27(2): 129-154.

Orbuch, T. L. (1997). People's Accounts Count: The Sociology of Accounts. Annual Review of Sociology 23: 455-478.

Parker, H. J., Aldridge, J., and Measham, F. (1998). Illegal Leisure: The Normalization of Adolescent Recreational Drug Use. Routledge.

Parker, H., Williams, L., and Aldridge, J. (2002). The Normalization of 'Sensible' Recreational Drug Use: Further evidence from the North West England longitudinal study. Sociology 36(4):941-964.

Peretti-Watel, P. (2003). Neutralization theory and the denial of risk: Some evidence from cannabis use among French adolescents. The British Journal of Sociology, 54(1), 21-42.

Potter, G. R. (2009). Exploring Retail-Level Drug Distribution: Social Supply, "Real” Dealers and the User/Dealer Interface. In Z. Demetrovics, J. Fountain, \& L. Kraus, eds, Old and New Policies, Theories, Research Methods and Drug Users Across Europe. Pabst Science Publishers.

Presser, L. (2008). Been a Heavy Life: Stories of Violent Men. University of Illinois Press.

Presser, L. (2009). The Narratives of Offenders. Theoretical Criminology 13: 177-200.

Presser, L., and Sandberg, S. (2015). Introduction: What is the Story? In L. Presser and S. Sandberg, eds, Narrative Criminology: Understanding Stories of Crime. New York Press. 
Rosenfeld, R., Jacobs, B. A., \& Wright, R. (2003). Snitching and the Code of the Street. British Journal of Criminology, 43: 291-309.

Sandberg, S. (2010). What Can "Lies" Tell Us About Life? Notes towards a Framework of Narrative Criminology. Journal of Criminal Justice Education, 21: 447-465.

Sandberg, S. (2012). Is cannabis use normalized, celebrated or neutralized? Analysing talk as action. Addiction Research \& Theory, 20(5), 372-381.

Schonbach, P. (1990). Account Episodes: The Management or Escalation of Conflict. Cambridge University Press.

Scott, M. B., and Lyman, S. M. (1970). Accounts, Deviance, and Social Order. Deviance and Respectability: 89-119. Basic Books.

Scully, D., and Marolla, J. (1984). Convicted Rapists' Vocabulary of Motive: Excuses and Justifications. Social Problems, 31: 530-544.

Shields, I.W. and Whitehall, G.C. (1994). Neutralization and Delinquency among Teenagers. Criminal Justice and Behavior, 21(2): 223-235.

Shover, N. (1996). Great pretenders: Pursuits and careers of persistent thieves. Boulder, CO: Westview Press.

Spradley, J. P. (1979). The Ethnographic Interview. Wadsworth.

Spradley, J. P. (1980). Participant Observation. Wadsworth.

Stadler, W. A., and Benson, M. L. (2012). Revisiting the Guilty Mind: The Neutralization of White-Collar Crime. Criminal Justice Review 37: 494-511.

Stets, J. E., and Burke, P. J. (2000). Identity theory and social identity theory. Social Psychology Quarterly. 63:224-37.

Sykes, G. M., and Matza, D. D. (1957). Techniques of Neutralization: A Theory of Delinquency. American Sociological Review, 22: 664-670. 
Tedeschi, J. T., and Reiss, M. (1981). Verbal strategies in impression management. In C. Antaki, ed, The Psychology of Ordinary Explanations of Social Behavior, 271-309. Academic Press.

Topalli, V. (2005). When Being Good is Bad: An Expansion of Neutralization Theory. Criminology 43: 797-835.

Veroff, J., Chadiha, L., Leber, D. and Sutherland, L. (1993). Affects and Interactions in Newlyweds' Narratives: Black and White Couples Compared. Journal of Narrative and Life History, 3(4): 361-390.

Webb, M., Deitzer, J., and Copes, H. (2017). Methamphetamine, symbolic boundaries, and using status. Deviant Behavior, 38(12), 1393-1405.

Weinstein, E. A., and Deutschberger, P. (1963). Some Dimensions of Altercasting. Sociometry, 26: 454-466.

Wright, R., Decker, S.H., Redfern, A., \& Smith, D.L. (1992). A Snowball's Chance in Hell: Doing Fieldwork with Active Residential Burglars. Journal of Research in Crime and Delinquency, 29: 148-161

Zerubavel, E. (1998). Language and Memory: 'Pre-Columbian' America and the Social Logic of Periodization. Social Research 65: 315-330. 